\title{
What Should be the Mask Types, Features and Standards Recommended for Health İnstitutions and for the General Population During the COVID-19 Pandemic?
}

\author{
COVID-19 Sürecinde Sağlık Kurumlarında ve Toplumda Önerilen Farklı Maske \\ Tipleri, Özellikleri ve Standartları Nasıl Olmalıdır?
}

\author{
Arife Özer'(ID), Mustafa Hacımustafaoğlu²(iD) \\ ${ }^{1}$ Clinic of Pediatrics, Sağlık Bilimleri University, Van Training and Research Hospital, Van, Turkey \\ ${ }^{1}$ Division of Pediatric Infectious Diseases, Department of Pediatrics, Uludag University School of Medicine, Bursa, Turkey
}

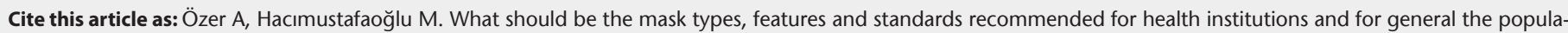
tion during the COVID-19 pandemic? J Pediatr Inf 2020;14(3):e150-e154.
\end{abstract}

Introduction: Masks can be used both for the protection of healthy persons (worn for self-protection when in contact with an infected person) and for source control (worn by an infected person to prevent transmission to others). However, other personal and community level preventive measures should also be taken to prevent transmission of COVID-19 and also other respiratory viruses. In order to prevent the transmission of COVID-19 from person to person, besides masks, hand hygiene, physical distance, and compliance with other infection prevention and control measures are also critical.

All over the world, the reliability, quality and standards of masks, which are the most important personal protective equipment, have become an issue to be taken into consideration in the COVID-19 pandemic.

What are the mask types and by whom should they be used? For the COVID-19 infection, different masks can be used to prevent acquiring infection. Masks can be used for aiming both healthcare professionals and the general pub- lic. However, the masks recommended for healthcare professionals and for the general public differ. In addition, mask recommendations for high-risk people in the general public may be different from the other people in the community.

a) Medical masks; Medical masks are also known as surgical masks or procedural masks. In this article, medical mask and surgical mask are used as synonymous. These masks are usually rectangular shaped and can be flat or pleated.

Medical masks are recommended for healthcare professionals and patients in hospitals. The types of masks recommended to patients and medical masks recommended to healthcare professionals may also differ. A health personnel, in this manner, means a health worker (physician, nurse, social worker, nurse, hospital cleaning staff) who provides care and services to patients in or out of the hospital. Type I mask (to prevent the infection from spreading from the infected person to others) is recommended for patients. For healthcare professionals, a Type II or Type II R medical mask (both to prevent the spread of infection to others and to protect

\section{Correspondence Address / Yazışma Adresi}

Mustafa Hacımustafaoğlu

Uludağ Üniversitesi Tıp Fakültesi,

Çocuk Sağlığı ve Hastalıkları Anabilim Dalı,

Çocuk Enfeksiyon Hastalıkları Bilim Dalı,

Bursa-Türkiye

E-mail: mkemal@uludag.edu.tr 
persons against infected droplets that may be produced by infected patients) is recommended. Type II R medical mask is recommended for operation rooms. However, in case of aerosol generated procedure, respirators (FFP 2-3 or N95-99 type masks) should be used. Targeted continuous use of medical masks, is defined as the practice of wearing a medical mask by all healthcare professionals and caregivers working in clinical areas throughout the entire shift and during all routine medical activities. Staff not working in clinical areas do not need to use medical masks during routine non-medical activities (such as administrative staff). Healthcare workers who care for a suspected or confirmed patient with COVID-19 infection, should also take contact and droplet precautions in addition to the mask.

It is not necessary for everyone in the community to wear a medical mask for the prevention of COVID-19 infection. Medical masks are also recommended in the general public, for elderly persons $>60$ years, immunocompromised patients and people with comorbidities such as cardiovascular disease or diabetes mellitus, chronic lung disease, cancer and cerebrovascular disease. In addition, medical masks can also be used in the general public, in crowded environments with poor conditions, and in environments with high population density (for example, refugee camps, camp-like environments, people living in congested conditions) and in situations where individuals cannot maintain a physical distance of at least 1 meter (such as public transport). However, in case of shortage of medical masks, these should be reserved for healthcare workers and people at risk.

b) Respirators (FFP 2-3 and N 95-99 type masks): The respirators are also termed as FFP2 or FFP3 masks (in Europe), or N95 or N99 masks (in the USA). These masks are recommended in high-risk situations where aerosol generating procedures (such as aspiration, intubation, nebulization, during COVID-19 PCR sampling, eye and throat examinations). Compared to medical masks, the respirators fit better to face and provides higher filtration efficiency. Thus, higher and more guaranteed protection is provided.

c) Cloth masks: Cloth masks can also be called non-medical masks or fabric masks. Unlike medical or FFP/N95 type masks, cloth masks are not considered as part of the personal protective equipment group and are also not considered as medical equipment. Cloth masks are not recommended for protection for the healthcare personnel and in hospital settings.

Cloth masks are generally made of normal fabric and/or non-woven fabrics. In the general public, it is used only for resource control (preventing/reducing spread of infection from an infected people). However, in terms of personal protection, it may not be effective enough. When using cloth masks, it is always necessary to pay attention to physical distance and hand hygiene rules.

Mask standards: During the COVID-19 pandemic process, different mask types were put on sale and into use. Unfortunately, it is not clear whether most of these are standardized. Many masks do not have standard package inserts on or on their boxes. It should be kept in mind that masks that do not ensure standards, will not have the expected anti-protective properties.

The procedures and principles regarding the design and production of personal protective equipment available on the market, the protection of the health and safety of the users and the free movement of personal protective equipment are defined in the 2016/425 (EU) regulation. Personal protective equipment (mask, gloves, goggles, overalls, helmets, shoes, etc.) used in accordance with the Personal Protective Equipment Regulation must have a CE certificate. CE certificate is a mark that indicates compliance with health, safety and environmental protection standards for products sold within the borders of the European Union.

Medical mask standards: The performance characteristics of medical masks are tested according to a set of standard test methods (ASTM F2100, EN 14683 or equivalents) aimed taking into account filtration efficiency capacity, adequate breathability and optionally liquid penetration resistance. Medical masks should be CE certified masks produced according to TS EN 14683 standard. Medical masks are designed to limit the transmission of infectious agents from personnel to patients and from patients to personnel in all medical environments. They are intended for single use only and their sterilization is not recommended. Depending on the usage conditions, their usage life may decrease. For medical (surgical) masks; according to the official Turkish State Supply Office (Devlet Malzeme Ofisi), the surgical mask standards generally required are as follows: the mask should be made of three-layer with non-woven polypropylene containing material, and should be suitable for continuous use for 6-8 hours. They should be anti-allergic, not containing fiber-glass, natural rubber, latex, fine fiber materials. They have a liquid barrier feature. Medical masks have been tested for their ability to block droplets (3 micrometers in size; EN 14683 and ASTM F2100 standards) and particles (0.1 micrometers in size; ASTM F2100 standard only). Masks should block droplets and particles and also be comfortable to breathe by allowing air to pass throu$\mathrm{gh}$. Medical masks are regulated as medical devices and they are considered as personal protective equipment.

Medical masks are generally produced using non-woven fabrics mainly containing polypropylene material. The advantageous features of nonwoven fabrics are as follows: they are air permeable, they have good bacterial filtration efficiency 
capacity (submicron filtration property is generally $>98 \%$ ), they have good barrier property more than cotton and polyester. They are disposable fabrics, and their cost is low. They can also be produced from materials other than polypropylene (such as polystyrene, polyethylene, polyester).

Medical masks usually consist of 3 layers as outer-middle-inner layer. The outer layer: it usually consists of polypropylene produced from non-woven melt fabric by the spunbond method. This layer can be colored. It is generally harder and water-repellent compared to other layers. The middle layer: it is a more fluffy layer with high fiber density for better filtration. It also contains polypropylene, produced from non-woven fabric with the meltblown method. It weighs $25-35 \mathrm{gr} / \mathrm{m}^{2}$. This layer plays a critical role of better filtration capacity and increases the cost of a quality mask. This layer looks thicker in appearance, and should not appear transparent when viewed from behind. The inner layer: it is a layer that is generally not chemically treated. It is softer, it should be anti-allergic, and not irritate the skin, the mouth and the nose. Fit is also a nonwoven fabric, polypropylene material with spunbond approach. Outer and inner layers are $15-25 \mathrm{gr} / \mathrm{m}^{2}$. In medical masks, the amount of bioburden allowance, according to the standards should be $<30 \mathrm{CFU} / \mathrm{gr}$. When using the medical masks, the inner layer of a medical mask should be worn over the mouth and nose. Reversing the mask (for example, wearing the outer layer over the nose and mouth) is not suitable and may not provide adequate protection. Generally, the threads of medical masks are tied to the inner layer, and the colored face often shows the outer layer. The outer layer should be waterproof up to a certain pressure.

Medical masks, according to TS EN 14683 standard, regarding to the bacterial filtration efficiency (BFE), breathability (differential pressure), splash resistance, microbial cleaning (amount of bioburden). According to these criteria, 3 types are determined as; Type I (bacterial filtration rate 95\%), Type II (bacterial filtration rate 98\%) and Type II R (bacterial filtration rate $98 \%$ and high liquid resistance). Type I (to prevent the infection spreading from infected person to others) is recommended for patients. Type II and II R are recommended for medical personnel, and Type II R is used in operation rooms. According to another classification (ASTM F 2100-07) medical masks are divided into 3 types as low, medium and high-level barrier masks. Generally and roughly, Type I, II and II R masks; corresponds to low, medium and high-level barrier masks, respectively.

Respirators (FFP 2-3 and N95-99 type masks): These are masks that have been produced according to TS EN 149 standard and received CE certificate for Europe. Their Filtering Face Piece (FFP) features are classified as FFP1, FFP2, FFP3 according to the European Agency for Safety and Health at Work:
European Occupational Health and Safety and Health Agency (EU-OSHA). It shows how much of the particles below 0.3 micron can be filtered. In our country and Europe, the latest standard of respirators is the N149: $2001+\mathrm{A} 1: 2009$ standard. According to the US National Institute for Occupational Safety and Health: (NIOSH) Standard respirators are classified as N95, N99, N100. There may be other similar standards in other countries of the world. Generally, FFP2 (filtration rate about 94\%) masks correspond to N95 masks, and FFP 3 (filtration rate $99.95 \%$ ) masks correspond to $\mathrm{N} 99$ or $\mathrm{N} 100$ masks. In this article, respirator, FFP2, FFP3 and N95 type masks are used in the same sense.

Respirator group masks are generally 5 layers. They are created by non-woven fabrics using various technological methods. Thermoforming is applied in their production processes, and they are produced as 3 dimensional shape. In medical masks, filtration tests are usually performed aiming with 3 micrometer particles, while respirators (such as FFP and N95) are performed with much smaller solid particles (such as 0.075 micrometers). Therefore, in respirators, more effective filtration is provided. In addition, in medical masks, filtration tests are performed on a cross-sectional surface, while in respirators (such as FFP and N95) they are tested across the entire mask surface. For this reason, FFP type masks provide a more guaranteed filtering than medical masks. These masks fit better on the face and in this respect provide a higher level of protection than medical masks.

Understanding of some abbreviations presented in the mask are as follows: NR: non reusable (disposable), V: valve, D: passing the dolomite test (passing the dolomite clogging test-Dolomite occlusion test). Masks that passed the dolomite test have a relatively longer use time, they can be used up to 8 hours. Mask with valve ensures more comfortable breath for the wearer, it protects the wearer, but if the wearer is infected, he or she can infect their surroundings. Therefore, masks with valve are not recommended for COVID-19 infection. If a mask with valve is used, a suitable medical mask should be worn upon the respirator with valve to protect the environment. The standards and features of the respirator must be specified on the mask. Respirators, whose standards are not specified, should not be used. Respirators are also for single use. However, some researchers are working on using these masks more than once by disinfecting them without disturbing their properties. These masks should not be washed, cleaned with disinfected solutions, or folded.

Cloth masks: They can be produced from a wide variety of materials including non-woven fabrics (such as polypropylene), or normal textile (such as cotton, silk, polyester, etc.). The unlimited combination of fabrics and materials that can be used can lead to different mask quality and properties, inc- 
luding variable filtration and breathability features. There are no generally accepted international standards for cloth masks. However, a non-medical (cloth) mask standard has been developed by the French Standardization Association (AFNOR Group). AFNOR Group defines minimum performance in terms of filtration (solid particle filtration or droplet filtration being at least $70 \%$ ), and breathability characteristics (such as maximum pressure difference as $0.6 \mathrm{mbar} / \mathrm{cm}^{2}$, maximum breathing resistance $2.4 \mathrm{mbar}$ and a maximum exhalation resistance of 3 mbar).

It has been shown that the filtration level (filtration efficiency; FE) of different cloth masks are very variable and varies between $0.7 \%$ and $60 \%$. The higher the filtration efficiency value results the more a barrier feature provided by the mask. Breathability is the ability to breath easily through the mask material. Breathability is the difference in pressure on the $2 \mathrm{si}$ des of the mask while wearing the mask and breathing, and it can be reported in milibar (mbar) or Pascal (Pa). Values are generally notified for the entire mask area or one mask area $\left(\mathrm{mbar} / \mathrm{cm}^{2}\right.$ or $\left.\mathrm{Pa} / \mathrm{cm}^{2}\right)$. The acceptable breathability of a medical mask should be below $49 \mathrm{~Pa} / \mathrm{cm}^{2}$. For non-medical cloth masks, an acceptable pressure difference over the entire mask should be less than $100 \mathrm{~Pa}$. Commercial cotton fabric masks are generally very breathable (more comfortable to breathe), but offer lower filtration. The filter quality factor known as " $\mathrm{Q}$ factor" is a commonly used filtering quality factor. The $Q$ factor is a common function of filtration efficiency (FE) and breathability, together. Higher $\mathrm{Q}$ value indicates better protection. According to expert consensus opinion, a cloth mask is recommended to have at least $3 \mathrm{Q}$ factor value. Approximate $Q$ factor values of different types of fabric masks are as follows: polypropylene nonwoven spunbond fabric; 16.9 , various cotton fabrics; 5.4-7.6, silk; 2.8 , polyester (knitted) 6.8, cellulose (such as napkin, hand towel); 5.1-4.3, gauze/fine muslin; 0.47, nylon (such as exercise pants); 0.4. FE values can be increased by folding the cloth masks. However, folding can make breathability more difficult. This can be assessed simply by bringing the folded fabric closer to the nose and mouth and looking at breathing difficulty. Fabric masks, which are fabricated products, can sometimes be applied with antibacterial finishes or chemical treatments with a cooling finish to ensure a more comfortable use in summer. It is not preferred that the mask cloth material be elastic. Elastic cloth masks will stretch when worn on the face, resulting in increased pore size and lower filtration efficiency throughout use. In addition, elastic materials can deteriorate over time and are sensitive to washing at high temperatures.

Cloth masks should ideally have a minimum of three layers. The inner layer of the mask is in contact with the face (mouth and nose) of the wearer. It should be made of a non-allergenic, hydrophilic, non-fiber producing material (e.g. cotton or cotton blends). The middle hydrophobic layer should consist of a polypropylene nonwoven or cotton material that can induce better filtration and/or retain droplets. The outer layer should be made of hydrophobic material (e.g. polypropylene, polyester, or mixtures of them) that limits the penetration of external contaminated secretions into the user's nose and mouth. Three-layer cloth masks can be made in the form of a pocket consisting of a inner and outer layer. A middle layer made of hydrophobic material with high filtration properties can be placed in the middle pocket by the user. Cloth masks should only be used by one person and not shared by anyone else. If the fabric layers look noticeably worn, it is appropriate to dispose of the mask.

It should be preferred that the fabrics used in making cloth masks are washable, and it is useful to know the highest allowable washing temperature. It is suitable to be washed at $60^{\circ} \mathrm{C}$ with soap or laundry detergent. Ironing can be done if necessary and if the mask fabric is suitable. Non-woven polypropylene spunbond fabrics can be washed at temperatures as high as $125^{\circ} \mathrm{C}$. It is necessary to avoid excessive rubbing of nonwovens (without too much rubbing, stretching or squeezing). Non-woven polypropylene spunbond and cotton combination masks can withstand high temperatures, steam or boil. In the absence of hot water, the mask can be washed with soap/detergent at room temperature, and then, a) it can be kept in boiling water for one minute, or b) soak the mask in $1 / 50$ bleach/tap water (1000 ppm chlorine, $0.1 \%$ chlorine solution) for one minute, and then the mask can be rinsed thoroughly with normal water.

\section{References}

1. World Health Organization (WHO). Advice on the use of masks in the context of COVID-19. Interim Guidance, 5 June 2020. Geneva: World Health Organization, 2020. [CrossRef]

2. World Health Organization (WHO) The World Health Report 2006 working together for health. Geneva: World Health Organization, 2006. [CrossRef]

3. http://tmo.org.tr/images/editorimages/Y\%C3\%9CZ\%20MASKELER\%C4\%BO\%20GENEL\%20B\%C4\%BOLG\%C4\%BOLEND\%C4\%BORME.pdf (Erişim tarihi: 05.10.2020). [CrossRef]

4. World Health Organization (WHO). Information Note COVID-19 and NCDs. Geneva: World Health Organization, 2020. Available from: https://www.who.int/docs/default-source/inaugural-whopartners-forum/covid-19-and-ncds---final--- corr7.pdf?sfvrsn=9b65e287_1\&download=true (Erişim tarihi: 04.07.2020). [CrossRef]

5. European Standards. UNE EN 14683:2019+AC:2019. Medical Face Masks - Requirements and Test Methods. Available from: https://www. en-standard.eu/une-en-14683-2019-ac-2019-medical-face-masksrequirements-and-test-methods/(Erişim tarihi: 04.07.2020). [CrossRef]

6. F23 Committee, n.d. Specification for Performance of Materials Used in Medical Face Masks. ASTM International. Available from: https://www. astm.org/standardization-news/?q=features/standards-medical-face-masks-and-protective-clothing-html (Erişim tarihi: 16.10.2020). [CrossRef] 
7. https://www.eso.org.tr/storage/file/ff9668dbf2ae42a18f66e723ecf41a8b.pdf (Erişim Tarihi: 05.10.2020). [CrossRef]

8. https://www.turkloydu.org/tr-tr/yayinlar/makaleler/2020/koruyucu-maskeler-hakk\%C4\%B1nda-bilgilendirme.aspx. (Erişim Tarihi: 05.10.2020). [CrossRef]

9. National Institute for Occupational Safety and Health (NIOSH). NIOSH Guide to the Selection and Use of Particulate Respirators. Department of Health and Human Services (DHHS) NIOSH publication number 96101, 1996. Available from: https://www.cdc.gov/niosh/docs/96-101/ default.html (Erişim Tarihi 16.10.2020). [CrossRef]

10. British Standard. BS EN 149:2001+A1:2009. Respiratory protective devices-Filtering half masks to protect against particles-Requirements, testing, marking. European CommitteeforStandardization. Availablefrom: https://shop.bsigroup.com/ProductDetail?pid=000000000030178264 (Erişim tarihi: 04.07. 2020). [CrossRef]

11. https://www.hopkinsmedicine.org/health/conditions-and-diseases/ coronavirus/coronavirus-face-masks-what-you-need-to-know (Erişim tarihi: 03.10. 2020). [CrossRef]

12. https://www.mayoclinic.org/diseases-conditions/coronavirus/in-depth/coronavirus-mask/art-20485449 (Erişim tarihi: 01.10.2020). [CrossRef]

13. AFNOR. 2020. SPEC S76-001: Masque barrière. Guide d'exigence minimales, de méthode d'essais, de confection et d'usage. Available from: https://www.snof.org/sites/default/files/AFNORSpec-S76-001-MasquesBarrieres.pdf (Erişim tarihi: 10.10.2020). [CrossRef]
14. Jung H, Kim JK, Lee S, Lee J, Kim J, Tsai P, et al. Comparison of filtration efficiency and pressure drop in anti-yellow sand masks, quarantine masks, medical masks, general masks, and handkerchiefs. Aerosol Air Qual Res 2014;14:991-1002. [CrossRef]

15. Rengasamy S, Eimer B, Shaffer RE. Simple respiratory protection--evaluation of the filtration performance of cloth masks and common fabric materials against 20-1000 nm size particles. Ann Occup Hyg 2010;54:789-98. [CrossRef]

16. Jang JY, Kim SW. Evaluation of filtration performance efficiency of commercial cloth masks. J Environ Health 2015;41:203-15. [CrossRef]

17. Podgórski A, Bałazy A, Gradoń L. Application of nanofibers to improve the filtration efficiency of the most penetrating aerosol particles in fibrous filters. Chemical Engineering Science 2006;61:6804-15. [CrossRef]

18. Zhao M, Liao L, Xiao W, Yu X, Wang H, Wang Q, et al. Household materials selection for homemade cloth face coverings and their filtration efficiency enhancement with triboelectric charging. Nano Lett 2020;20:5544-52. [CrossRef]

19. Reusability of Facemasks During an Influenza Pandemic: Facing the Flu, 2006. National Academies Press, Washington, D.C. Available from: https://www.nap.edu/catalog/11637/reusability-of-facemasks-during-an-influenza-pandemic-facing-the-flu (Erişim tarihi: 15.10.2020). [CrossRef]

20. Liao L, Xiao W, Zhao M, Yu X, Wang H, Wang Q, et al. Can N95 respirators be reused after disinfection? How many times? ACS Nano 2020;14:6348-56. [CrossRef] 